\title{
Correction to: PSO-Based Initial SOC and Capacity Optimization for Stationary Energy Storage Systems in DC Electric Railway System
}

\author{
Kisuk Kim ${ }^{1}$. Jaewon $\mathrm{Kim}^{2}$ - Changmu Lee ${ }^{2}$ Joorak Kim² ${ }^{2}$ Hansang Lee ${ }^{3}$
}

Published online: 15 June 2021

(c) The Korean Institute of Electrical Engineers 2021

\section{Correction to: Journal of Electrical Engineering \& Technology https://doi.org/10.1007/s42835-021-00746-0}

Due to an unfortunate oversight the acknowledgement has been omitted. It should read:

Acknowledgements This research was funded by the Ministry of Land, Infrastructure and Transport's Railway Technology Research Project, "Development of Real Time Simulator and Analysis Model for Railway Power System (21RTRP-B146034-04)".

The original article has been corrected.
Publisher's Note Springer Nature remains neutral with regard to jurisdictional claims in published maps and institutional affiliations.

The original article can be found online at https://doi.org/10.1007/ s42835-021-00746-0.

Hansang Lee

hslee@ semyung.ac.kr

Kisuk Kim

kks1213@korea.ac.kr

Jaewon Kim

youngkjw@krri.re.kr

Changmu Lee

cmlee@krri.re.kr

Joorak Kim

jrkim@krri.re.kr

1 School of Electrical Engineering, Korea University, Seoul, Korea

2 Korea Railroad Research Institute, Uiwang, Korea

3 Department of Electrical Engineering, Semyung University, Jecheon, Korea 